\title{
EFFECT OF CARBON NANOTUBES ON THE MECHANICAL FRACTURE PARAMETERS AND MICROSTRUCTURE OF ALKALI ACTIVATED SLAG MORTARS
}

\author{
Rovnaník $\mathbf{P}^{1}$, Bayer $\mathbf{P}^{2}$, Topolář $\mathbf{L}^{3}$, Šimonová $\mathbf{H}^{4}$, Schmid $\mathbf{P}^{5}$ \\ ${ }^{1}$ Faculty of Civil Engineering, Brno University of Technology, Czech Republic \\ ${ }^{2}$ Faculty of Civil Engineering, Brno University of Technology, Czech Republic \\ ${ }^{3}$ Faculty of Civil Engineering, Brno University of Technology, Czech Republic \\ ${ }^{4}$ Faculty of Civil Engineering, Brno University of Technology, Czech Republic \\ ${ }^{5}$ Faculty of Civil Engineering, Brno University of Technology, Czech Republic
}

\begin{abstract}
Alkali activated slag has a great potential to be used in practice. The mechanical properties and application possibilities of alkali activated slag composites are very similar to ordinary cement based concrete. However, the major disadvantage of alkali activated slag is an increased shrinkage, which results in microcracking and deterioration of tensile and bending properties. The study investigates the possibility of using carbon nanotubes (CNTs) as nanosized reinforcement to reduce the cracking tendency of alkali activated slag composite. The effect of CNTs was evaluated by means of mechanical fracture tests and microscopic observations. Compressive strength has increased with $0.5 \%$ addition of CNTs but higher content of CNTs causes a deterioration of the compressive strength. Modulus of elasticity was also slightly higher in case of the mixture with 0.5\% of CNTs. Effective fracture toughness and fracture energy values are in both cases lower than with reference mixture. Therefore, it can be assumed that such amounts of CNTs do not improve fracture parameters of AAS material. The micrographs revealed that CNTs were not able to eliminate the stress caused by a drying shrinkage of AAS matrix and still some cracks can be observed in the matrix.
\end{abstract}

Keywords: Slag, Alkaline activation, Carbon nanotubes, Microstructure and Fracture parameters

\section{INTRODUCTION}

Alkali-activated aluminosilicate materials represent an alternative to ordinary Portland cement-based materials, reducing the environmental impact of the building industry and offering new and superior properties. Alkali-activated slag (AAS) is based on granulated blast furnace slag, which can be activated by alkali hydroxides, carbonates, or most preferably, silicates [1]. The mixture sets to form very stable products. Their properties depend on a number of factors such as chemical and mineralogical composition, type, composition and amount of alkali activator, curing conditions etc.

The mechanical properties and application possibilities of alkali activated aluminosilicate materials are very similar to ordinary cement based concrete. However, in contrast to Portland cement based binders, alkali activated aluminosilicates offer superior properties such as higher corrosion resistance against acid or sulphate attack [2-5] and also higher resistance to elevated temperatures and fire [6-8]. The major disadvantage is an increased shrinkage, especially in case of alkali activated slag. This effect is caused by both autogeneous and drying shrinkage and it finally results in volume contraction, microcracking and deterioration of tensile and bending properties [1].
Our current project is devoted to the investigation of the effects of carbon nanotubes (CNTs) used as nanosized reinforcement on the properties of alkali-activated aluminosilicate materials. The main motivation for the research is to reduce the cracking tendency and improve the tensile properties of these materials. The application of CNTs in cement matrix was studied by several researchers who observed partial improvement of the mechanical properties [9-11]. This paper presents and discusses the comparison of selected mechanical fracture parameters of the material and parameters of acoustic emission signals for different quantity CNTs. These results are also correlated with microstructural observations based on SEM and mercury intrusion porosimetry.

\section{EXPERIMENTAL PROCEDURES}

\subsection{Materials and Sample Preparation}

The alkali-activated slag mortars used were composed of granulated blast furnace slag finely ground to a specific surface area of $380 \mathrm{~m}^{2} \cdot \mathrm{kg}^{-1}$ and sodium silicate solution in which $\mathrm{SiO}_{2} / \mathrm{Na}_{2} \mathrm{O}=1.6$. Quartz sand with a maximum grain size of $2.5 \mathrm{~mm}$ was used as aggregate. Multi-wall carbon nanotubes combined with carboxymethylcellulose as dispersing agent (Arkema) were dissolved in water to prepare 5\% solution of CNTs. The content of CNTs was 0.5 and $1 \%$ respective to the amount of slag. The results were compared with reference mixture without CNTs. 
The mixture was placed into prismatic moulds $40 \times 40 \times 160$ $\mathrm{mm}$ to set and hardened specimens were immersed in water for 27 days. One set of specimens was tested for the fracture properties immediately after the prisms had been pulled out of the water (V series), while the other set was allowed to dry spontaneously under ambient conditions for $24 \mathrm{hrs}$ prior to testing ( $\mathrm{S}$ series).

Table 1: Composition of the mixtures

\begin{tabular}{|l|l|l|l|}
\hline CNTs content & $0 \%$ & $0.5 \%$ & $1 \%$ \\
\hline Slag $(\mathrm{g})$ & 450 & 450 & 450 \\
\hline Water glass $(\mathrm{g})$ & 180 & 180 & 180 \\
\hline CNTs' solution $(\mathrm{g})$ & 0 & 45 & 90 \\
\hline Quartz sand (g) & 1350 & 1350 & 1350 \\
\hline Water (ml) & 95 & 62 & 32 \\
\hline
\end{tabular}

\subsection{Testing Procedure}

Experiments were carried out on a Heckert FPZ 10/1 mechanical testing machine with the measuring range 0 $1000 \mathrm{~N}$. The effective fracture toughness value was determined using the Effective Crack Model [12], which combines the linear elastic fracture mechanics and crack length approaches. During the experiment, the three-point bending test was performed on specimens with a central edge notch cut to a depth of about $1 / 3$ of specimen depth. The loaded span was $120 \mathrm{~mm}$. A load-deflection (F-d) diagram, which was used for the calculation of elasticity modulus from the first (almost linear) part of the F-d diagram, and of effective fracture toughness, was recorded using an HBM SPIDER 8 device. An estimate of fracture energy was obtained from the $\mathrm{F}-\mathrm{d}$ diagram according to the RILEM method (using work-of-fracture value) [13]. The compressive strength values were also determined for all specimens on the fragments remaining after the fracture experiments had been performed.

The initiation of cracks during the fracture tests was also monitored by the acoustic emission (AE) method. AE is the term for the noise emitted by materials and structures when they are subjected to stress. Stresses can be mechanical, thermal or chemical in nature. The noise emission is caused by the rapid release of energy within a material due to events such as crack formation that occur under applied stress, generating transient elastic waves which can be detected by piezoelectric sensors. In this case the $\mathrm{AE}$ method detects and characterizes the development of the fracture cracking process and evaluates the activity of the damage only during its course [14].

Pore distribution was evaluated by means of mercury intrusion porosimetry analysis using Micromeritics Poresizer 9300 porosimeter. The morphology of the microstructure was investigated by scanning electron microscope Tescan MIRA3 XMU.

\section{RESULTS AND DISCUSSION}

\subsection{Fracture Tests}

The results of the fracture tests are presented in Table 2 and corresponding figures. The values of bulk density, compressive strength, Young's modulus, effective fracture toughness and specific fracture energy were determined. All of the results in the figures are given in the form of arithmetic means (obtained from 3 independent measurements) and the standard deviations are shown as error bars. Table 2 presents a comparison of these parameters for both the $\mathrm{S}$ and $\mathrm{V}$ series, where all the values are calculated relative to the samples without CNTs (CNT $0 \%)$.

Table 2: Relative mean values [\%] of determined parameters with respect to the reference mixture without CNTs

\begin{tabular}{|l|l|l|l|l|}
\hline \multirow{2}{*}{ Parameter } & \multicolumn{2}{|l|}{ S series } & \multicolumn{2}{l|}{ V series } \\
\cline { 2 - 5 } & $\begin{array}{l}\text { CNT } \\
0.5 \%\end{array}$ & CNT 1\% & $\begin{array}{l}\text { CNT } \\
0.5 \%\end{array}$ & CNT 1\% \\
\hline $\begin{array}{l}\text { Compressive } \\
\text { strength }\end{array}$ & 110.0 & 86.6 & 148.0 & 124.0 \\
\hline $\begin{array}{l}\text { Modulus of } \\
\text { elasticity }\end{array}$ & 123.0 & 88.7 & 107.5 & 99.9 \\
\hline $\begin{array}{l}\text { Fracture } \\
\text { toughness }\end{array}$ & 90.0 & 72.1 & 93.8 & 87.5 \\
\hline $\begin{array}{l}\text { Fracture } \\
\text { energy }\end{array}$ & 65.6 & 64.4 & 92.6 & 79.5 \\
\hline
\end{tabular}

The addition of $0.5 \%$ CNTs to the amount of slag leads to increase of compressive strength and modulus of elasticity values by 10 and $23 \%$, respectively in case of $\mathrm{S}$ series (48 and $8 \%$, respectively for $\mathrm{V}$ series). The addition of $1 \%$ CNTs with respect to the amount of slag leads to a decrease of these parameter values by 13 and $11 \%$, respectively in case of $\mathrm{S}$ series. In case of $\mathrm{V}$ series compressive strength value increases by $24 \%$ and elasticity modulus value is the same as in case without addition of CNTs. When we compare elasticity modulus values for both series, values for $\mathrm{V}$ series are twice higher than the values for $\mathrm{S}$ series, both with and without CNTs.

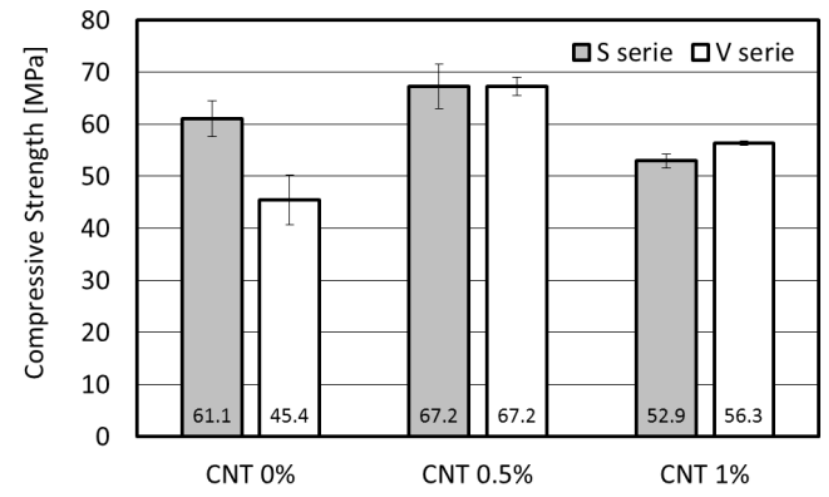

Fig. 1: Determined values (mean \pm standard deviation) of compressive strength 


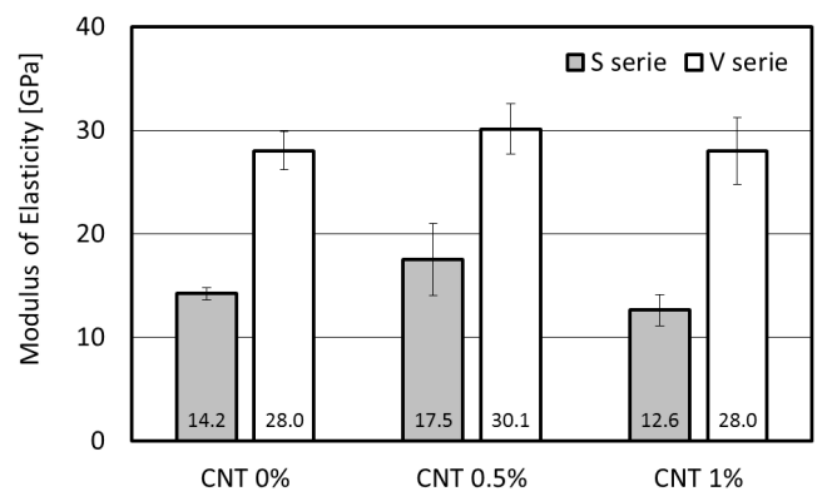

Fig. 2: Determined values (mean \pm standard deviation) of Young's modulus

Values of fracture toughness and fracture energy were lower in both contents of CNTs and for both $\mathrm{S}$ and V series. Fracture toughness values decreased by 10 up to $28 \%$ in case of S series and by 6 up to $12 \%$ for V series. Fracture energy values decreased by $35 \%$ in case of S series and by 7 up to $20 \%$ for $\mathrm{V}$ series. When we compare fracture energy values for both series, values for $\mathrm{V}$ series are less than half of the values in case of $\mathrm{S}$ series irrespective of the CNTs content.

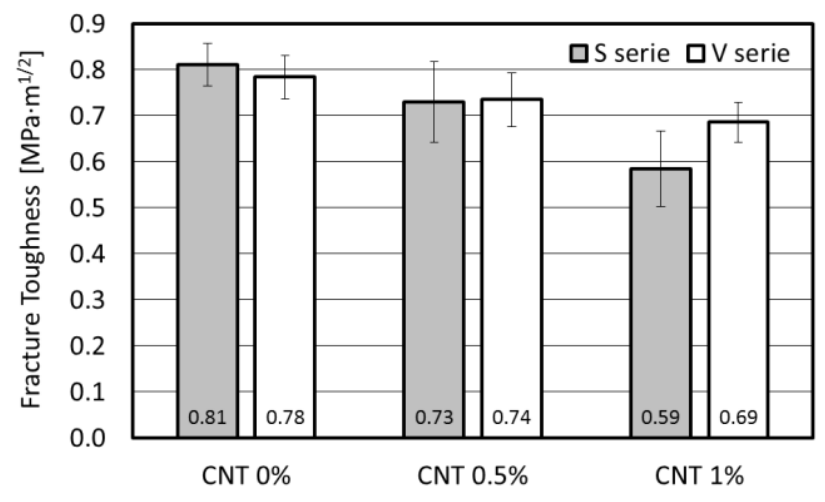

Fig. 3: Determined values (mean \pm standard deviation) of effective fracture toughness

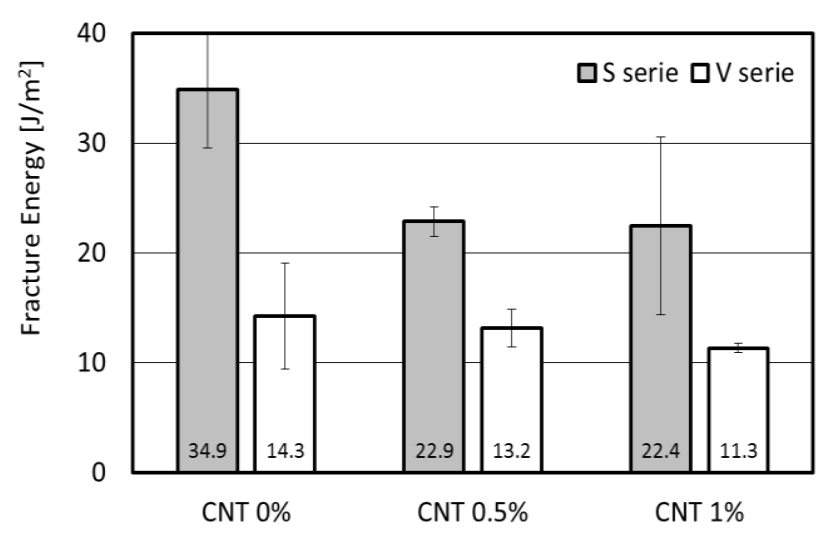

Fig. 4: Determined values (mean \pm standard deviation) of specific fracture energy

\subsection{Acoustic Emission Activity}

During fracture tests an acoustic emission activity was recorded. The guard sensor eliminated mechanical and electrical noise. Acoustic emission system DAKEL with software XEDO has been applied for continuous monitoring of concrete structure loading. Four acoustic emission sensors were placed on specimen surface. To describe the origin of micro cracks during stress, we focused on the number of $\mathrm{AE}$ overshoots.

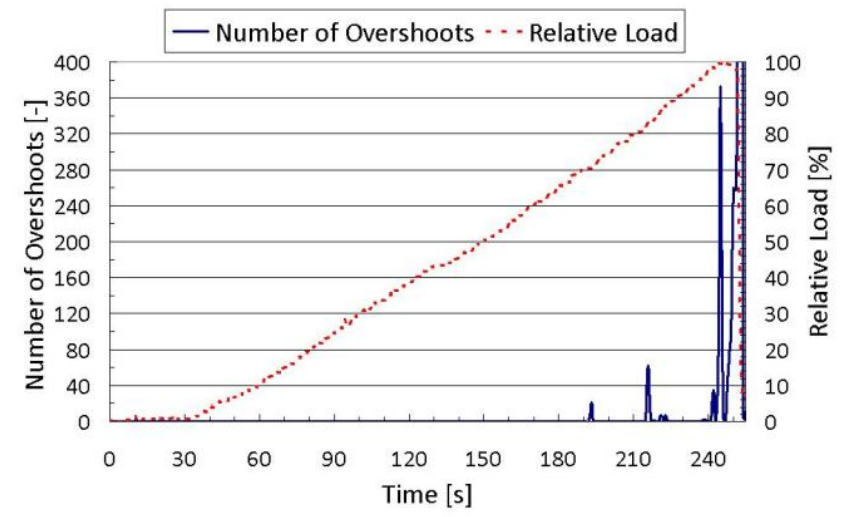

Fig. 5: Number of AE overshoots and relative load vs. time for specimens without CNTs

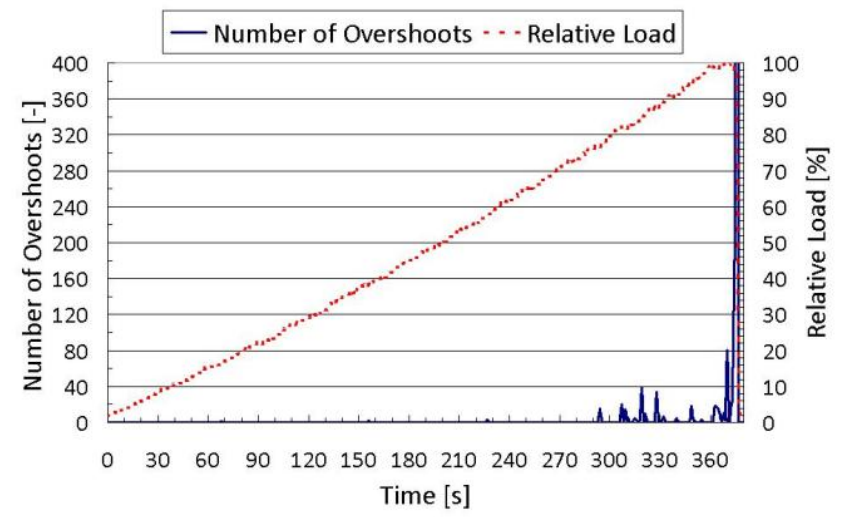

Fig. 6: Number of AE overshoots and relative load vs. time for specimens with $0.5 \% \mathrm{CNTs}$

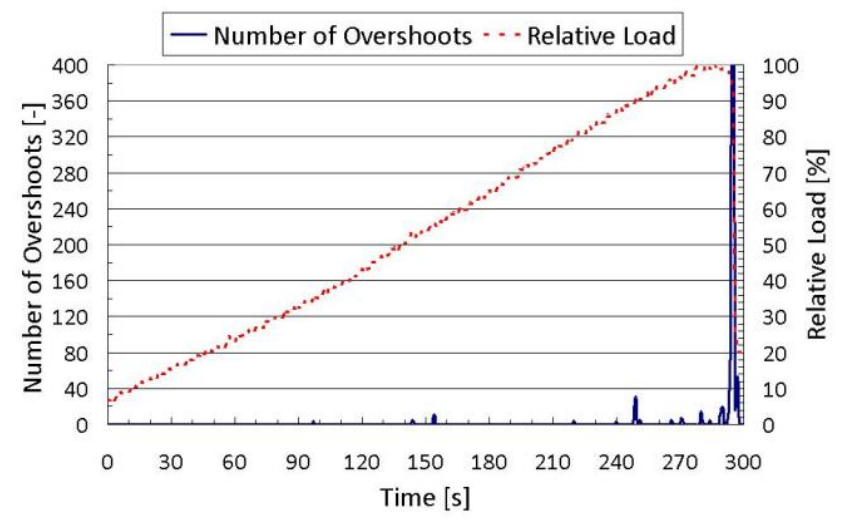

Fig. 7: Number of AE overshoots and relative load vs. time for specimens with $1 \% \mathrm{CNTs}$ 
Figures 5-7 show a number of AE overshoots and relative load vs. time measured during the fracture test. The number of overshoots represents the number of $\mathrm{AE}$ signal which exceed a preset threshold. A higher number of $\mathrm{AE}$ overshoots means higher number of emerging cracks in the tested specimen. Figures 5-7 present the test progress from the beginning of load to the fracture event, when the load reaches the maximum value. It is evident that the highest $\mathrm{AE}$ activity is achieved just before the fracture of the specimen bar. Specimens with 0\% CNT have the highest number of overshoots before the fracture, but with increasing amount of CNTs the number of overshoots decreases.

\subsection{Pore Distribution and Microstructure}

Pore structure of tested samples was measured by means of mercury intrusion porosimetry. Comparison of cumulative pore volume vs. pore diameter for mixtures without and with 0.5 and $1 \%$ of CNTs is presented in Fig. 8. The curves show that AAS matrix has the maximum pore volume in the region of large pores with diameter $>0.3 \mu \mathrm{m}$. There can be found very little difference between the curves. Total pore volume is $0.041 \mathrm{~cm}^{3} \square \mathrm{g}^{-1}$ in average. The only difference in pore volume has been observed for pores around $10 \mu \mathrm{m}$ in diameter. The samples with addition of CNTs are bit more porous than the reference sample in this range of pore size. Surprisingly, it does not correspond to the compressive strengths, which are usually the function of porosity. Therefore, decrease in compressive strength for specimens with CNTs must be attributed to a different microstructure and morphology of the bulk matrix rather than to the effect of porosity.

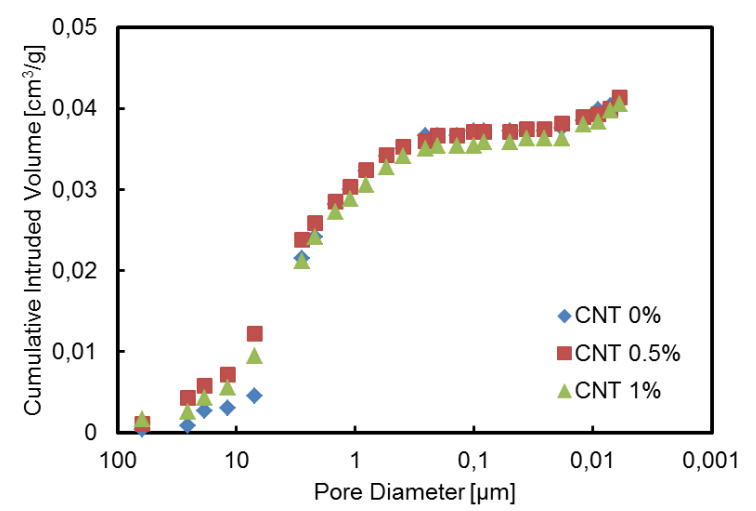

Fig. 8: Comparison of pore distribution for specimens without and with CNTs

Morphology of AAS matrix is presented in Fig. 9. On the left micrograph there is a reference matrix with cracks. The binder itself is very compact with quite homogenous amorphous structure of $\mathrm{C}-\mathrm{A}-\mathrm{S}-\mathrm{H}$ gel. Right micrograph represents the AAS containing $1 \%$ of CNTs dispersed in the matrix. It is obvious that content of CNTs has a considerable effect on the morphology of alkali-activated slag. The, which probably cause slight deterioration of the mechanical properties.
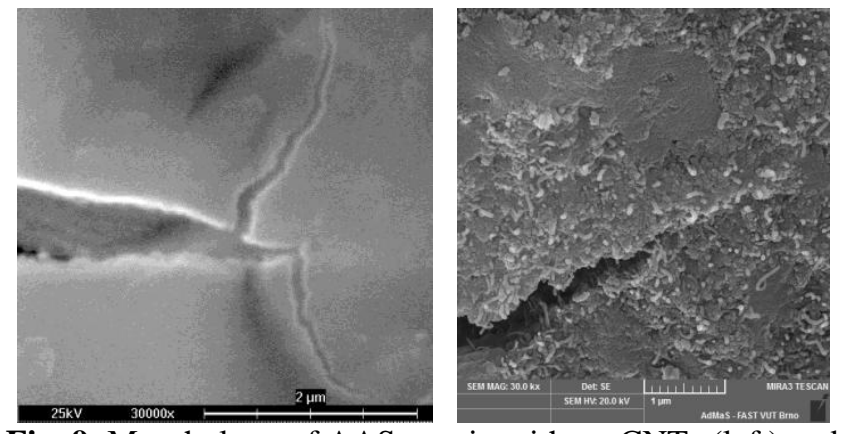

Fig. 9: Morphology of AAS matrix without CNTs (left) and with $1 \%$ of CNTs (right)

However, despite such excess of nanotubes with immense tensile properties it is not possible to eliminate the stress caused by a drying shrinkage of AAS matrix. Figure 10 shows in detail a crack in the matrix overbridged by several single nanotubes, suggesting a pull-out of CNTs from the matrix, and therefore, not very good CNT-matrix connectivity. However, some nanotubes are bit narrower in diameter, indicating that slippage may have occurred between the inner and the outer nanotube shells thereby preventing their full pull-out from the matrix. The mechanism of this effect was explained by Yamamoto et al. [12] when they studied the failure mechanism of MWCNTs during crack opening in an alumina matrix.

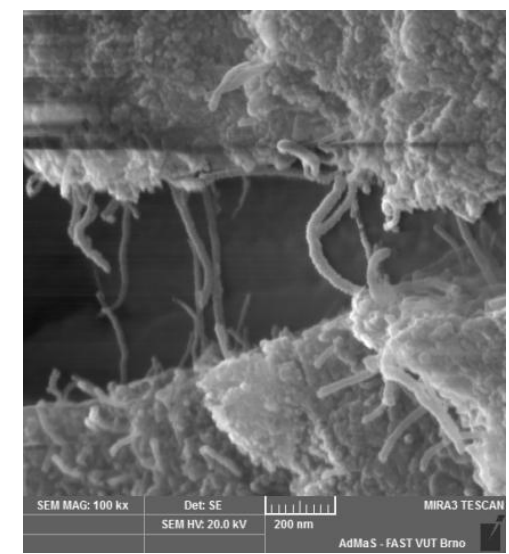

Fig. 10: Detail of CNTs bridging the crack in the AAS matrix

\section{CONCLUSIONS}

In this paper, we have investigated the mechanical fracture properties of alkali-activated slag composite with addition of carbon nanotubes and their correlation to the microstructure. Based on the experimental results presented here, the following conclusions can be made:

- Compressive strength has increased with $0.5 \%$ addition of CNTs for both $\mathrm{S}$ and $\mathrm{V}$ series. A significant improvement was achieved especially with $\mathrm{V}$ series, where the value was equal to the one achieved for $\mathrm{S}$ series. Higher content of CNTs causes a deterioration of the compressive strength.

- Modulus of elasticity was also slightly higher in case of the mixture with $0.5 \%$ of CNTs. However, the values for $\mathrm{V}$ series were twice as high as those achieved for $\mathrm{S}$ series, indicating that water 
saturated AAS composites are much more brittle. Effective fracture toughness and fracture energy values are in both cases lower than with reference mixture. Therefore, it can be assumed that such amounts of CNTs do not improve fracture parameters of AAS material.

- Changes in microstructure were studied by scanning electron microscopy. The micrographs revealed the marked difference in morphology of AAS with and without CNTs. In case of material modified by the addition of CNTs, the matrix was less compact with lots of imperfections. However, carbon nanotubes were not able to eliminate the stress caused by a drying shrinkage of AAS matrix and still some cracks appeared in the matrix.

\section{ACKNOWLEDGEMENTS}

The authors would like to acknowledge greatly the financial support from the Czech Science Foundation for the project No. 13-09518S.

\section{REFERENCES}

[1]. SHI, C., KRIVENKO, P. V., ROY, D. Alkali-activated cements and concretes. Taylor \& Francis, Oxon, 2006.

[2]. BYFORS, K., KLINGSTEDT, G., LEHTONEN, V., PYY, H., ROMBEN, L. Durability of Concrete Made with Alkali Activated Slag. ACI SP Proceedings 1989, 114, 1429-1468.

[3]. BAKHAREV, T., SANJAYAN, J. G., CHENG, Y.-B. Resistance of alkali-activated slag concrete to acid attack. Cement and Concrete Research 2003, 33, 1607-1611.

[4]. BAKHAREV, T., SANJAYAN, J. G., CHENG, Y.-B. Sulfate attack on alkali-activated slag concrete. Cement and Concrete Research 2002, 32, 211-216.

[5]. ROVNANÍKOVÁ, P., BAYER, P. Corrosion resistance of alkali activated aluminosilicate materials. In: Innovations and Developments in Concrete Materials and Construction, Proceedings of the International Conference, Dundee, UK: Thomas Telford, London 2002, 373-381.

[6]. ZUDA, L., ROVNANÍK, P., BAYER, P., ČERNÝ, R. Effect of High Temperatures on the Properties of Alkali Activated Aluminosilicate with Electrical Porcelain Filler. International Journal of Thermophysics 2008, 29, 693-705.

[7]. ROVNANÍK, P., BAYER, P., ROVNANÍKOVÁ, P. Characterization of alkali activated slag paste after exposure to high temperatures. Construction and Building Materials 2013, 47, 1479-1487.

[8]. GUERRIERI, M., SANJAYAN, J., COLLINS, F. Residual strength properties of sodium silicate alkali activated slag paste exposed to elevated temperatures. Materials and Structures 2010, 43, 765-773.

[9]. KONSTA-GDOUTOS, M. S., METAXA, Z. S., SHAH, S. P. Highly dispersed carbon nanotube reinforced cement based materials. Cement and Concrete Research 2010, 40, 1052-1059.

[10]. SEAZ DE IBARRA, Y., GAITERO, J. J., ERKIZIA, E., CAMPILLO, I. Atomic force microscopy and nanoindentation of cement pastes with nanotube dispersions. Physica Status Solidi 2006, 203, 1076-1081.

[11]. MAKAR, J.M., BEAUDOIN, J.J. Carbon nanubes and their application in construction industry. In: Nanotechnology in construction, Proceedings of the $1^{\text {st }}$ International Symposium on Nanotechnology in Construction, RSC, 2004, pp. 331-341.

[10]. KARIHALOO, B. L. Fracture mechanics of concrete. Longman Scientific \& Technical, New York, 1995.

[11]. RILEM Committee FMT 50, Determination of the fracture energy of mortar and concrete by means of threepoint bend test on notched beams, Material Structures. 18 (1985) 285-290.

[12]. GROSSE, Ch. U., OHTSU, M. Acoustic Emission Testing. Springer-Verlag, Berlin, 2008.

[13]. YAMAMOTO, G., LIU, S., HUB, N., HASHIDA, T., LIU, Y., CHENG, Yan. Prediction of pull-out force of multi-walled carbon nanotube (MWCNT) in sword-insheath mode. Computational Materials Science 2012, 60, 712.

\section{BIOGRAPHIES}

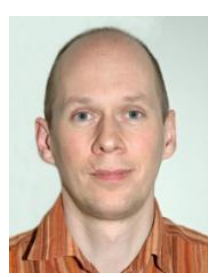

materials.
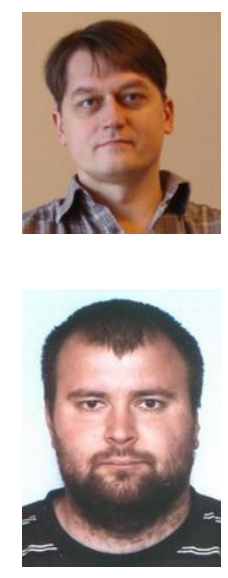

stress.

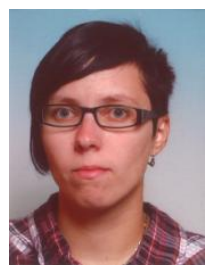

based composites.

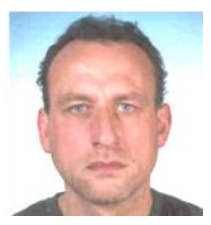

Pavel Rovnaník received the $\mathrm{PhD}$ degree in chemistry from the MU, Czech Republic. $\mathrm{He}$ is currently working as associate professor at FCE BUT. His research interests concern the application of geopolymers in civil engineering and high temperature behaviour of building

Patrik Bayer received his $\mathrm{PhD}$ degree from the FCE BUT, Czech Republic. He is currently working as assistant professor at FCE BUT. He is a specialist in SEM and porosimetry measurements.

Libor Topolár r received the $\mathrm{PhD}$ degree in Physical and Building Materials Engineering from the BUT. He is currently working at FCE BUT. His research interests concern the application of acoustic nondestructive methods in civil engineering and behaviour of building materials under

Hana Šimonová received the $\mathrm{PhD}$ degree from FCE BUT, Czech Republic in 2013. She is currently working as assistant professor at the Institute of Structural Mechanics, FCE BUT. Her research interests are in the field of fatigue and fracture mechanics of quasi-brittle silica-

Pavel Schmid is currently working as associate professor at FCE BUT. He is a specialist in mechanical testing of building materials and structures. 